\title{
Internet Usage and Its Addiction Level among Students in a Selected College in Ras Al Khaimah Emirate: A Cross-Sectional Study
}

\author{
Rabab Gad Abd El-Kader ${ }^{1} \&$ Victoria Funmilayo Hanson ${ }^{2}$ \\ ${ }^{1}$ Assistant Prof. of Community Health Nursing, RAK College of Nursing, RAK Medical and Health Sciences \\ University, United Arab Emirates \\ ${ }^{2}$ Assistant Prof. of Maternal and Child Health Nursing, RAK College of Nursing, RAK Medical and Health \\ Sciences University, United Arab Emirates \\ Correspondence: Rabab Gad Abd El-Kader, Assist. Prof of Community Health Nursing in College of Nursing, \\ RAK Medical and Health Sciences University; Lecturer of Community Health Nursing, Faculty of Nursing, \\ Mansoura University, United Arab Emirates. E-mail: rabab@rakmhsu.ac.ae; victoria@rakmhsu.ac.ae
}

Received: March 4, 2019

Accepted: April 22, 2019

Online Published: April 28, 2019

doi:10.20849/ijsn.v4i2.560

URL: https://doi.org/10.20849/ijsn.v4i2.560

\begin{abstract}
Background and aim: The internet is a worldwide area network that connects computer system throughout the world providing a variety of information and communication. Internet addiction is defined as any online-related, compulsive behavior which interferes with normal living and causes severe stress on family, friends, loved ones, and one's work environment. Aim: This study assessed the internet usage and its addiction level among university students in a selected university in Ras Al Khaimah, United Arab Emirate. University students are highly predisposed to internet addiction which can affect their personal, family, educational, interactive and societal life.

Study design: A cross-sectional design .The sample of the study consisted of 110 nursing students who were selected using convenient sample. Internet addiction test, internet usage questionnaire and student attitude scale were used as data collection instruments.

Results: The findings showed that more than half (50.9\%) of students were aged $21-<25$ years, with more than two- fifth (45.5\% of them being average online internet user. Less than two-third (62.7\%) of students had favorable attitude towards internet usage. There is a positive correlation between internet addiction score and age of the study group with no statistically significant difference

Conclusions: the study concluded that nursing students are average internet users, they have favorable attitude to internet use, with positive correlation between internet addiction score and age, though experiencing occasional problems. The use of social networking sites, especially by the young people, should be done sparingly so as not to provoke extreme behaviors and negative impact to their education performance and social life that can lead to destruction of the life of youths globally as revealed in this study Internet addiction is a serious problem among university students generally which indicates the need for more public attention and resources to develop effective prevention/intervention strategies.
\end{abstract}

Keywords: addiction, Internet usage, student, college, cross-sectional

\section{Introduction}

"The Internet is so big, so powerful and pointless that for some people it is a complete substitute for life. -Andrew Brown"

Internet addiction is defined as any online-related, compulsive behavior which interferes with normal living and causes severe stress on family, friends, loved ones, and one's work environment. Internet addiction has been called Internet dependency and Internet compulsivity. Addiction can be effectively prevented, treated and managed by the health care professional in combination with family or peer support (Tikhonov \& Bogoslovskii, 2015). In the last few decades, the Internet has facilitated daily life in many aspects and it has become increasingly prevalent. Internet usage has increased in areas such as: health, education, banking, transportation, research and personal data investigation. Mobile devices play an important role in this major increase in Internet usage (Abdullah \& Cem, 2017). 
The internet is a worldwide area network that connects computer system throughout the world. It comprises several high bandwidth data line that includes the internet backbone. These lines are connected to major internet hubs that distribute data to other location such as web servers and internet service providers (Arvind et al., 2014). A modem may be a part of the computer or a stand-along device that is connected to the computer and phone line (Isman \& Dabaj, 2004).The term World Wide Web (WWW) refers to the collection of public Web sites connected to the Internet worldwide, together with the client devices such as computers and cell phones that access its content. For many years it has become known simply as "the Web."

With all these advantages, there are some disadvantages of internet usage which affects the globe widely. The inquisitiveness to know and learn new things slowly ended up with addiction. In general addiction is a complex disease, often chronic in nature, which affects the functioning of the brain and body. It can also cause serious damage to families, relationships, schools, workplaces and neighborhoods. The most common symptoms of addiction are severe loss of control, continued use despite serious consequences, preoccupation with using, failed attempts to quit, tolerance and withdrawal. Addiction can be effectively prevented, treated and managed by health care professionals in combination with family or peer support (Julia and Mark, 2014).

Addiction is a chronic disorder with biological, psychological, social and environmental factors influencing its development and maintenance. About half the risk for addiction is genetic. Genes affect the degree of reward that individuals experience when initially using a substance (e.g., drugs) or engaging in certain behaviors (e.g., gambling), as well as the way the body processes alcohol or other drugs. Internet addiction has been called Internet dependency and Internet compulsivity. By any name, it is a compulsive behavior that completely dominates the addict's life. Internet addicts make the Internet a priority more important than family, friends, and studies. The Internet becomes the organizing principle of addicts 'lives (Konstantinos et al., 2008). In a true addiction, a person becomes compulsively dependent upon a particular kind of stimulation to the point where obtaining a steady supply of that stimulation becomes the sole and central focus of their lives. The addict increasingly neglects his studies, relationships and ultimately even his health in his drive to remain stimulated (Kuss et al., 2014).

University students are especially vulnerable to developing dependence on the Internet, more than most other segments of the society. This can be attributed to several factors including the following: Availability of time; ease of use; unlimited access to the Internet; the psychological and developmental characteristics of young adulthood; limited or no parental supervision; some courses are Internet-dependent, from assignments and projects to communication with peers and mentors; the Internet offering a route of escape from examination stress, all of which make Internet overuse a significant cause of concern for parents and faculty (Lee et al., 2014). This health concerns necessitate urgent awareness, prevention and prompt intervention to curb the menace.

Students use mobile phones while walking to class, riding on a bus, or waiting for an elevator. These micro time slots 'in which people can engage in a mind-boggling array of online activities were not previously available. That can be an enormous advantage for educators eager to draw on spaced learning to improve student learning outcomes. But obsessive smart phone checking can also interfere with face-to-face relationships and impair academic performance (Lićwinko, Krajewska-Kułak \& Łukaszuk, 2011; Hasmujaj, E., 2016).

The statistics on the internet usage in the United Arab Emirates from 2013 to 2019. In 2015, shows that above seventy percent of the UAE inhabitants were internet users. This is expected to rise to eighty out of a hundred in 2019 (UAE: online penetration 2013-2019). The internet and American life projects survey (2011) reported that 78\% of American adult aged 18+ were internet users who at least occasionally use the internet to send and receive email (Cheng, Moore, \& Ruiz, 2012). The aim of the study is to assess the internet usage and its addiction level among undergraduates nursing students in a selected college in Ras Al Khaimah Emirate.

\subsection{Aim/Objectives}

To assess the internet usage and its addiction level among undergraduates in selected college in Ras Al Khaimah Emirate

1) To assess the internet usage amongst the students

2) To assess the level of internet addiction between undergraduates

3) To assess the student's attitude about internet usage

4) To associate the students' level of internet addiction with their demographic variables.

\subsection{Research Questions}

1) What are the internet usage among the students?

2) What are the level of internet addiction among students? 
3) What are the student attitude about internet usage?

4) Is there a correlation between student demographic data and their attitude and level of internet addiction?

\section{Method}

\subsection{Study Setting and Population}

This study was conducted at RAK College of Nursing, RAK Medical and Health Science University (RAKMHSU), UAE during the academic year 2018/2019. The study participants were the nursing students in different grades of the college selected using convenience sample, student's approval was obtained after due information was provided those who were present on the day of the survey participated in the survey. . Sample size was calculated online (http://www.openepi.com/SampleSize/SSPropor.htm) with the following: Sample Population size (for finite population correction factor or fpc) $(\mathrm{N})$ ): 130. Hypothesized \% frequency of outcome factor in the population (p): $59 \%+/-5$. Confidence limits as $\%$ of 100 (absolute $+/-\%$ ) (d): $5 \%$. Design effect (for cluster surveys-DEFF):1. Sample Size (n) for 99\% Confidence Level was 110.

2.2 Design

A cross-sectional survey was adopted.

\subsection{Data Collection}

Three data collection tools were used; structured self-administered questionnaire developed after reviewing the related literature consisted of two parts. The $1^{\text {st }}$ part includes students' demographic data as age, gender and residence. The $2^{\text {nd }}$ part includes internet usage among students which is composed of the kind of internet usage, the devices used for internet surfing, form of internet renew and period of internet usage. INTERNET ADDICTION TEST (IAT) (Young, 1998). A valid and reliable tool that comprises of 20 -item questionnaire with six Likert scales that measures mild, moderate, and severe stages of internet addiction. The upper the mark, the larger the level of addiction and the problems of internet usage. 20 - 49 score (ordinary on-line user and may surf the Network a bit too long at times, but have a control over usage.) $50-79$ (experiencing occasional or frequent problems because of the Internet that should consider their full impact on life): 80 - 100 (internet usage is causing significant problems in your life and should evaluate the impact of the Internet on your life). Student attitude scale was used to assess students' attitudes towards Internet, It consist of 23 items related to internet attitudes The interpretation of the Likert scale for the attitude score is as follows: unfavorable 0-38.9; moderately favorable 39-76.9 and favorable 77-115 (Internet World Stats, 2011b).

\subsection{Pilot Study}

Before putting the questionnaire in practice a pilot study on 10 students were conducted to test the validity and reliability of the questionnaire.

\subsection{Validity \& Reliability}

The Cronbach's alpha for reliability was 0.77 , while the content validity was assessed by three experts in nursing college.

\subsection{Procedure}

The survey was conducted in October 2018 among nursing students in the BSN program during the academic year 2018/2019. Data was collected after written consent was obtained, the students that took 5-7 minutes to complete the questionnaire.

\subsection{Ethical Considerations}

Approval from RAKMHSU-Research Ethical Committee of the university and permission letter from the dean of RAK college of Nursing was taken. Written consent was taken from the study participants. They were informed of confidentiality and their rights to reject participation.

\subsection{Data Analysis}

Statistical Package for social Science (SPSS) version 23 was utilized. Data was presented by descriptive statistics in the form of frequencies, percentages, means and standard deviations for quantitative variables. Correlation (r) test was used to assess correlation between student's attitude, level of internet addiction and demographic data. Statistical significance was considered at $\mathrm{p}$-value $\leqslant 0.05$. 


\section{Results}

Table 1. Distribution of the study group according to their demographic data

\begin{tabular}{lll}
\hline Characteristics & $\mathrm{N}(110)$ & $\%$ \\
\hline Age/years & \multicolumn{2}{l}{} \\
$17-<21$ & 45 & 40.9 \\
$21-<25$ & 56 & 50.9 \\
$25-33$ & 9 & 8.2 \\
\hline Mean \pm SD & $21.22 \pm 2.42$ \\
\hline Gender & \multicolumn{2}{|}{} \\
Male & 18 & 16.4 \\
Female & 92 & 83.6 \\
\hline Residence & \multicolumn{2}{|}{} \\
Home & 94 & 85.5 \\
Hostel & 16 & 14.5 \\
\hline
\end{tabular}

Table 1 displays the demographic data of the study group in which more than half $(50.9 \%)$ of them were in the age class of 21 to less than 25 years and the minority $(8.2 \%)$ of students in the age class of 25-33 years with a mean and standard deviation $21.22 \pm 2.42$. As regards to gender the most $(83.6 \%)$ of students were females. For residence, most of them stayed in their homes while only $14.5 \%$ stayed in the hostel.

Table 2. Distribution of the study group according to their internet usage

\begin{tabular}{lll}
\hline Items & $\mathrm{N}(110)$ & $\%$ \\
\hline Means of using internet * & 31 & 28.2 \\
Computer & 26 & 23.6 \\
$\quad$ Android & 77 & 70 \\
$\quad$ Apple & 6 & 5.5 \\
Tablet & & \\
\hline Duration of using internet & 6 & 5.6 \\
$<1$ year & 14 & 12.7 \\
$2-3$ years & 90 & 81.8 \\
$>\quad 3$ years & & \\
& & \\
\hline Main purpose of using the internet $*$ & 33 & 30 \\
To prepare assignments & 45 & 40.9 \\
To update knowledge & 42 & 38.2 \\
For Entertainment & 75 & 68.2 \\
For communication & & \\
\hline Day for recharge the internet & 67 & 60.9 \\
$<15$ days & 29 & 26.4 \\
1 month & 7 & 6.4 \\
$>1$ month & & \\
\hline & &
\end{tabular}




\begin{tabular}{lll}
\hline Every 6 month & 7 & 6.4 \\
\hline Money spent on internet recharge & 23 & 20.9 \\
$<100$ & 13 & 11.8 \\
$100-200$ & 31 & 28.2 \\
$200-300$ & 43 & 39.1 \\
$>300$ & & \\
\hline Place of using internet * & 73 & 66.4 \\
Home & 73 & 66.4 \\
college & 34 & 30.9 \\
Café & 38 & 34.5 \\
$\quad$ Library & 80 & 72.7 \\
your mobile phone & 38 & 34.5 \\
Friend's or family's house &
\end{tabular}

$\mathrm{NB}: *$ more than one option

Table 2 reveals that more than two-third (70\%) of the students had apple device for accessing the internet while the minority $(5.5 \%)$ had tablet. The majority $(81.8 \%)$ of students were internet user for more than 3 years, more than two-third (68.2\%) of student's main purpose of internet use is for communication, while $(40.9 \%)$ use it for knowledge update and less than one-third (30\%) use it for preparation of assignment. $60.9 \%$ recharged 15 days or less than while, $6.4 \%$ of them recharged one month more. Two-fifth $(39.1 \%)$ of the students spent more than 300 dirhams for recharging, while (11.8\%) spent 100-200 dirhams. As regards to place using internet the majority (72.7\%), (66.4\%) use mobile phone, at home and at college respectively.

Table 3. Correlation between attitude score and age of the study group

\begin{tabular}{lll}
\hline Items & Mean \pm SD & Pearson Correlation \\
& & Sig. \\
\hline Age & $\mathbf{2 1 . 2 2} \pm \mathbf{2 . 4 2}$ & $\mathbf{0 . 1 5 4}$ \\
\hline Attitude Score & $80.36 \pm 19.68$ & $>\mathbf{0 . 0 5}$ \\
\hline
\end{tabular}

Significant difference at $\mathrm{P} \leqslant 0.05$

Table 3 reveals that there is a positive correlation between attitude score of internet usage and the age of the study group with no statistically significant difference.

Table 4. Correlation between internet addiction score and age of the study group

\begin{tabular}{lll}
\hline Items & Mean \pm SD & Pearson Correlation \\
& & Sig. \\
\hline Age & $\mathbf{2 1 . 2 2} \pm \mathbf{2 . 4 2}$ & $\mathbf{0 . 0 6 8}$ \\
\hline Addiction score & $\mathbf{5 0 . 4 0} \pm \mathbf{1 8 . 0 1}$ & $>0.05$
\end{tabular}

Table 4 represents that there is a positive correlation between internet addiction score and age of the study group with no statistically significant difference 
Table 5. Correlation between attitude score and internet addiction score of the study group

\begin{tabular}{lll}
\hline Items & Mean \pm SD & Pearson Correlation \\
& & Sig. \\
\hline Addiction score & $\mathbf{5 0 . 4 0} \pm \mathbf{1 8 . 0 1}$ & -.093 \\
\hline Attitude Score & $\mathbf{8 0 . 3 6} \pm 19.68$ & $>.05$ \\
\hline
\end{tabular}

Table 5 shows that there is a negative correlation between attitude and internet addiction score of the study group with no statistically significant difference

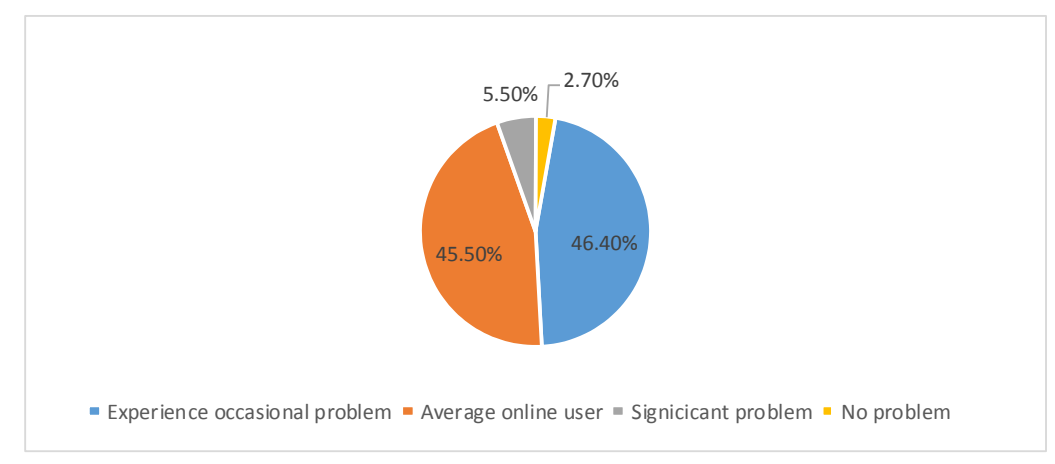

Figure 1. Internet addiction level

Figure 1 reveals the internet addiction level of the study group in which less than half (46.4\%) of students had experienced occasional problems, more than two-fifth $(45.5 \%)$ of them are average online user, the minority $(5.5 \%)$ had significant problem while the least $(2.7 \%)$ of students had no problems.

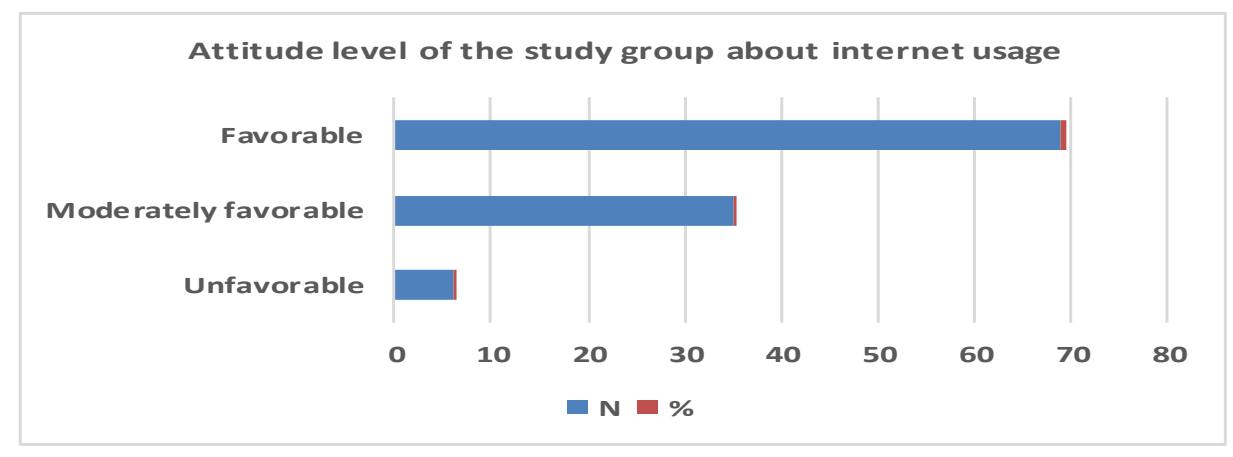

Figure 2. Attitude level of the study group about internet usage

Figure 2 represents the percentage distribution of students in terms of level of attitude. The data reveals that less than two-third (62.7\%) of students had favorable attitude, one-third (31.8\%) had moderately favorable attitude and the minority $(6 \%)$ of students had unfavorable attitude about internet usage

\section{Discussion}

This study examined the internet usage and its addiction level among students in selected college in Ras Al Khaimah Emirate. The demographic status showed that more than half of students were in age group of 21 to less than 25 years while the minority of students were in age group of 25-33years with a mean and standard deviation $21.22 \pm 2.42$, which corroborates with other findings in the literature that addictive internet use among adolescents in Wuhan occur in the same age group (Oberiri D. A, and Timothy O.I, 2018; Silvana Karacic et al., 2014; Williams et al., 2009). It was observed that majority of the participants who are females resides in their homes, this is in contrast to a study on factors influencing internet usage and addiction that shows more male than female use internet and may be addicted (Moschovitis et al., 1999). 
The type of gadgets for internet use in present study shows that more than two-third of the students use apple, there is no study to support or otherwise on the type of gadgets used, type of gadget is likely due to the current application in vogue by the people including both old and young. This study further reveals that majority of students have been using internet for more than 3 years. This was in agreement with Karthika et al. (2017) who did a descriptive study to assess the knowledge and attitude regarding internet usage and its addiction level among students studying in selected colleges of Ambala, Haryana. This finding confirms that more than two-third of student's main purpose of internet use is for communication rather than education which is in disparity to the results of a study that most of the students use this technology for course associated educational purpose and research needs though it differs with age, level of study and faculty (Venkata et al., 2014). Another study in contrast observed that university students use the internet for research, doing homework, accessing information, social networking and trading purposes (Tikhonov \& Bogoslovskii, 2015).

This study reveals that majority recharges for less than 15 days while few of them not recharging for more than one month due to the money spent for recharge, around two-fifth of students spend more than 300 dirhams and less than a quarter spent 100-200 dirhams for recharge. The amount of money spent by the students on recharging their phone may be due to the fact that the parent's income enables them to give allowance money since majority of the students are sponsored by the ministry of health which correlates with the results of a study that revealed that people with lower household monthly income of less than 2196 dirhams per month tend to spend lesser time using computers at home as compared to other household income groups (Isman \& Dabaj, 2004). Further the findings discovered that the daily average duration of internet usage variable is the dominant variable affecting their Internet use purpose. It has been observed that students who spend an hour or less on the Internet per day use it to do homework and the ones who spend more than an hour use the Internet to join social networking sites. This result conforms to other findings in the literature on evaluating the degree of mobile internet dependence of university students in the United States and Korea (Shek, Tang, and Lo, 2008; Lu Yu and Daniel Tan L. S. 2018).

Domicile of internet usage shows that the majority who represent two-third use internet on their mobile phone at home and college. This was in agreement with the findings of Chacko et al., (2015). Accordingly, there has been a well-documented increase in installing internet facilities in homes, offices, places of learning, in specialist businesses, such as internet cafes and computer game shops in the Emirates (Özmutaf, Özgür, \& Gökmen, 2008; Kaya, N. 2016).

The findings on internet addiction level of this study reveals that less than half of the students had experienced occasional problems, with more than two-fifth of them being average online user. This was in agreement with Julia and Mark, (2014) who found out more than half of students had faced occasional problems in usage, while the minority of students had none. The current study was supported by another study regarding the internet addiction behavior (Solhi, Farhandi \& Armoon, 2013). It also corroborate with Abdullah and Cem (2017) who identified relations between problematic mobile phone use and psychological parameters such as chronic stress, emotional stability, and depression in young women (Shin, 2014). Another study also found out a co-occurrence association exist between one's mental health state, the tendency toward somatization, anxiety, depression and excessive cell-phone use. Further the findings indicated that Internet addiction appeared to be a common problem in university students which specifies the need for more public attention and resources to develop effective prevention/intervention strategies. The resultant health and social consequences would be massive if no instant and rigorous actions are taken to control this epidemic (Rahardjo et al., 2016).

The attitude level of the study group reveals that about two-third of students had favorable attitude towards the internet usage, this may be due to the fact that, students are exposed to use internet early in this era of technology. This was in agreement with Julia and Mark (2014) who opined that the majority of students had moderately favorable attitude while minority of the students had unfavorable attitude. It also correlates with Arvind et al, (2014) whose participant's states that they feel happy and comfortable when they use the internet and that they support the use of the internet being the latest invention in this information era, they however few feel that they lose their feelings of time while using the internet. The result of this study reveals that there is a positive correlation between attitude score of internet usage and the age of the study group with no statistically significant difference, this agrees with Özmutaf, Özgür, \& Gökmen, 2008; Kaya, N. (2016) that indicated the participant's attitudes toward computer and internet usage were significantly related to age, the youngest participants are less than 30 years old significantly scored higher than the participants in the older groups of age more than 40 . In general internet and computer usage decrease by increasing age. The study reveals a positive association between internet addiction score and age of study group with no statistically significant difference. This can be described by middle age students' greater developmental dynamics, like having a stronger need to improve sense of identity, and more access to the internet, than younger students when they first entered into university, which agrees with Sahin et al., 
2013; Lopez-Fernandez, (2015) that identified age as one of the reasons that influenced internet addiction in freshmen university student's in China.

A systematic review also confirms that in the last decade the younger the age of first internet use the greater the inclination to internet addiction in Korea (Konstantinos, 2008). Further findings of this study shows that there is a negative relationship between attitude and internet addiction score of study group with no statistically significant difference which is in contrast with Center for Internet Addiction, (2017) that discloses that subjects' attitudes toward computer networks could clarify many aspects of internet addiction. Affective responses toward computer networks and internet addiction are not significant as actual behaviors on Internet usage and usefulness perceptions.

\section{Conclusion}

The study was carried out to assess internet usage and its addiction level among students in selected college in Ras Al Khaimah Emirate. Internet addiction is a growing problem among students undergoing professional courses which have psychological, physical and social impact in their life. . The use of social networking sites, especially by the young people, should be done sparingly so as not to provoke extreme behaviors and negative impact to their educational performance and social life leading to destruction of the life of youths globally as revealed in this study. There is a need to explore proactive interventions, awareness and recognition that both students and employees, could potentially become addicted to a technology that is being provided directly by the institution. There is also need to develop strategies for evidence-based interventions to tackle effects of internet usage and addiction among University students. Future studies could also focus on the relationship between Internet addiction and anxiety, depression and stress.

\section{Recommendations}

Based on the results of this study, the following recommendations have been made for further study:

- Nurse educators can develop health education materials like informational booklet, pamphlet for students which will help to them understand the need for identifying the problem and acceptance measures to prevent the internet addiction related issue among university nursing students.

- Continuing education programs should be conducted for nurses to update their knowledge regarding internet addiction and effects of internet usage on their health and educational performance.

- Nursing research regarding the internet usage and its addiction level among the college and school students can be conducted.

- The community health nurses working in the community area should be involved in raising the awareness among family members and parents by use of various awareness programs and by providing health education.

- A community health nurse can participate in social vigilance by periodic monitoring and taking necessary steps in the implementation of various policies and program implemented in the colleges to reduce the impact of internet usage and internet addiction

- Students are upcoming generation of a country so it is important that their knowledge regarding the internet usage and its addiction be enriched.so that they can act as change agents in the society

\section{Limitations}

Study was limited to selected college in the university hence it cannot be generalized...

\section{Acknowledgements}

Authors would like to acknowledge students who participated in the study. Conflicts of Interest Disclosure. Authors declare that there is no conflict of interest statement.

\section{References}

Apuke, O. D., \& Iyendo, T. O. (2018). University students' usage of the internet resources for research and learning: forms of access and perceptions of utility. Heliyon, 4(12). https://doi.org/10.1016/j.heliyon.2018.e01052

Bursten, J., \& Dombeck, M. (n.d.). Internet addiction and mental issues. Retrieved from https://www.mentalhelp.net/articles/introduction-to-internet-addiction/

Center for Internet Addiction. (2017). Dayu Internet Overuse Solution, the solution for internet overuse and online addiction. Retrieved from http://www.internetoveruse.com/? $\mathrm{p}=171$

Chacko, H., Joseph, J. T., Abraham, J., Aranha, P. R., \& Shetty, A. P. (2015, October). ILL Effects of Internet Addiction-Knowledge and Attitude among nursing students. Research Journal of Computer and Information 
Technology Sciences, 3(4), 1-4.

Cheng, K., Moore, A., \& Ruiz, C. (2012, June 19th). Media use and children: risks \& risky behavior. OHSU Department of Psychiatry.

Cheng, K., Moore, A., \& Ruiz, C. (2012, June 19th). Pew internet and American life projects survey: internet adoption 1995 - 2011. Retrieved from Pewinternet.org

Faruk, A., \& Güzeller, C. O. (2017). Demographic Factors Affecting Internet Using Purposes of High School Students in Malaysia. Journal of Educational Technology, 5(1).

Hasmujaj, E. (2016). Internet Addiction and Loneliness among Students of University of Shkodra. European Scientific Journal, 12(29). https://doi.org/10.19044/esj.2016.v12n29p397

Internet World Stats. (2011b). Internet Usage Statistics: The Internet big picture: World Internet users and population stats. Retrieved 13 September, 2011, from http://www.internetworldstats.com/stats.htm

Isman, A. (2004, October). Attitudes of Students towards Internet. Turkish online Journal of Distance Education, $5(4)$.

Isman, A., \& Dabaj, F. (2004). Attitudes of students towards Internet. Turkish Online Journal of Distance Education - TOJDE, 5(4). Retrieved from http://tojde.anadolu.edu.tr/tojde16/articles/dabaj.htm

Karthika et al. (2017) Adescriptive study to assess the knowledge and attitude regarding internet usage and its addiction level among students studying in selected colleges of Ambala, Haryana. World Journal of Pharmacy and Pharmaceutical Sciences, 6(9), 477-503. https://doi.org/10.20959/wjpps20179-9981

Kaya, N. (2016). Association between attitudes towards internet usage and health practices in high-school students in 2 schools in Turkey: A cross-sectional study. Eastern Mediterranean Health Journal, 22(11), 824-831. https://doi.org/10.26719/2016.22.11.824

Konstantinos, E. S., Evaggelia, D. D., Dimitrios, A. B., Odysseas, D. M., \& Nikiforos, V. A. (2008). Internet Addiction among Greek Adolescent Students. Cyberpsychology and Behavior, 11(6), 653-657. https://doi.org/10.1089/cpb.2008.0088

Kuss, D. J., Griffiths, M. D., Karila, L., \& Billieux, J. (2014). Internet addiction: a systematic review of epidemiological research for the last decade. Curr Pharm Des., 20, 4026-4052. https://doi.org/10.2174/13816128113199990617

Lee, J. Y., Shin, K. M., Cho, S. M., \& Shin, Y. M. (2014). Psychosocial risk factors associated with internet addiction in Korea. Psychiatry Investig, 11, 380-386. https://doi.org/10.4306/pi.2014.11.4.380

Lićwinko, J., Krajewska-Kułak, E., \& Łukaszuk, C. (2011). Internet addiction among academic youth in Białystok. Progress in Health Sciences, 1(1), 124-130.

Lopez-Fernandez, O. (2015). Cross-cultural research on internet addiction: a systematic review. Int Arch Addict Res Med., 1, 2. https://doi.org/10.23937/2474-3631/1510011

Moschovitis, C. J. P., Polle, H., Schuyler, T., \& Senft, T. M. (1999). From Sputnik to the ARPA net: 1957-1969. In C. J. P. Moschovitis, H. Polle, T. Schuyler \& T. M. Senft (Eds.), History of the Internet: A Chronological 1843 to the present (pp. 33-62). Calofornia, USA: ABC-CLIO, Inc.

Nwagwu, W., Adekannbi, J., \& Bello, O. (2009). Factors influencing use of the internet: A questionnaire survey of the students of University of Ibadan, Nigeria. The Electronic Library, 27(4). https://doi.org/10.1108/02640470910979651

Özmutaf, M. N., Özgür, Z., \& Gökmen, F. (2008) General point of view of the university students on computer usage in context of personal health in Turkey. Ege Journal of Medicine, 47(2), 81-6.

Rahardjo, D., Sumardjo, P. D., Lubis, D. P., \& Harijati, I. S. (2016). Internet access and usage in improving students' self-directed learning in Indonesia open university. Turkish Online Journal of Distance Education, 17(2). https://doi.org/10.17718/tojde.90196

Sahin, S., Ozdemir, K., Unsal, A., \& Temiz, N. (2013). Evaluation of mobile phone addiction level and sleep quality in university students. Pak J Med Sci, 29, 913-8. https://doi.org/10.12669/pjms.294.3686

Sharma1, A., Sahu1, R., Kasarl, P. K., Sharma, R., et al. (2014). Internet addiction among professional courses students. EJ Manager. Retrieved from www.ejmanager.com/mnstemps /67/67-1400998592.pdf

Shek, D. T. L., Tang, V. M. Y., \& Lo, C. Y. (2008). Internet addiction in Chinese adolescents in Hong Kong: 
assessment, profiles, and psychosocial correlates. The Scientific World Journal, 8, 776-787. https://doi.org/10.1100/tsw.2008.104

Shin, L. Y. (2014). A Comparative Study of Mobile Internet Usage between the U.S. and Korea. Journal of European Psychology Students, 5(3), 46-55. https://doi.org/10.5334/jeps.cg

Solhi, M., Farhandi, H., \& Armoon, B. (2013). Internet addiction among B.Sc. students in Health Faculty, Tehran University of Medical Sciences. Razi Journal of Medical Sciences, 20(106), 40-47.

Srijampana, V. V. G. R., Endredd, A. R. et al. (2014). Prevalence and patterns of internet addiction among medical students. Medical Journal of Dr. D.Y. Patil University, 7(6), 0975-2870. https://doi.org/10.4103/0975-2870.144851

Tikhonov, M. N., \& Bogoslovskii, M. M. (2015). Internet addiction factors. Automatic Documentation and Mathematical Linguistics, 49(3), 96-102. https://doi.org/10.3103/S0005105515030073

UAE. (n.d.). Online Penetration 2013-2019. Retrieved from http://www.statista.com>internet $>$ demographics \& use statistics

Young, K. (1998). Assessment of Internet Addiction. The Center for Internet Addiction Recovery. https://doi.org/10.1037/t41898-000

Yu, L., \& Shek, D. T. L. (2018). Testing Longitudinal Relationships between Internet Addiction and Well-Being in Hong Kong Adolescents: Cross-Lagged Analyses Based on three Waves of Data. Child Indicators Research, 11(5), 1545-1562. https://doi.org/10.1007/s12187-017-9494-3

\section{Copyrights}

Copyright for this article is retained by the author(s), with first publication rights granted to the journal.

This is an open-access article distributed under the terms and conditions of the Creative Commons Attribution license (http://creativecommons.org/licenses/by/4.0/). 